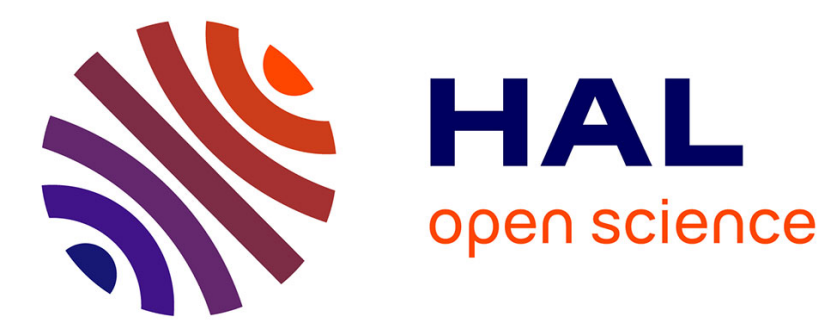

\title{
Collaborative Exploration in a Multi-Scale Shared Virtual Environment
}

Thi Thuong Huyen Nguyen, Cédric Fleury, Thierry Duval

\section{To cite this version:}

Thi Thuong Huyen Nguyen, Cédric Fleury, Thierry Duval. Collaborative Exploration in a Multi-Scale Shared Virtual Environment. 3DUI 2012, Mar 2012, Orange County, United States. hal-00671823

HAL Id: hal-00671823

https://hal.inria.fr/hal-00671823

Submitted on 18 Aug 2012

HAL is a multi-disciplinary open access archive for the deposit and dissemination of scientific research documents, whether they are published or not. The documents may come from teaching and research institutions in France or abroad, or from public or private research centers.
L'archive ouverte pluridisciplinaire HAL, est destinée au dépôt et à la diffusion de documents scientifiques de niveau recherche, publiés ou non, émanant des établissements d'enseignement et de recherche français ou étrangers, des laboratoires publics ou privés. 


\section{Collaborative Exploration in a Multi-Scale Shared Virtual Environment}

\author{
Thi Thuong Huyen Nguyen* \\ IRISA - INRIA Rennes Bretagne Atlantique
}

\author{
Cédric Fleury ${ }^{\dagger}$ \\ IRISA - INSA de Rennes
}

\author{
Thierry Duval ${ }^{*}$ \\ IRISA - Université de Rennes 1
}
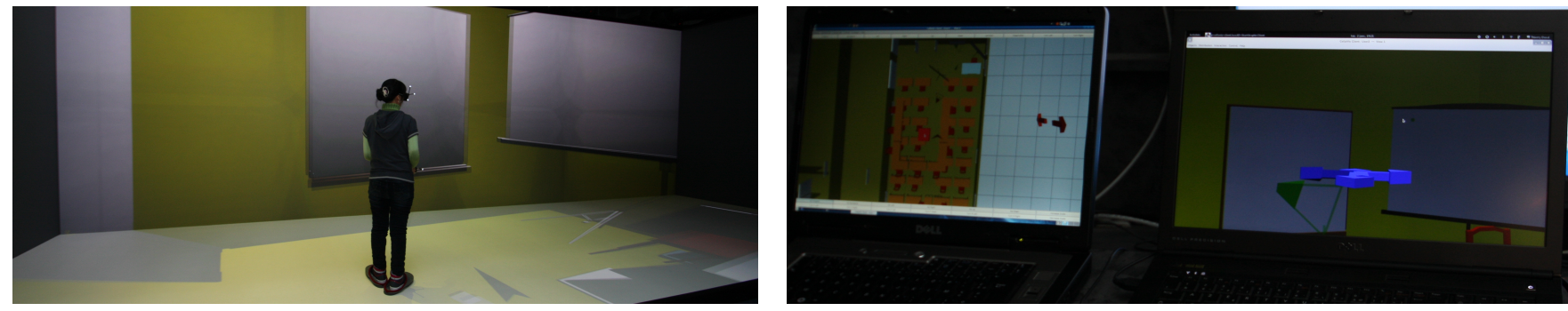

Figure 1: The main user in immersion and the helping user in front of the desktop views

\begin{abstract}
For the 3DUI 2012 contest, we propose a set of metaphors that enable two users to collaborate to find hidden targets in a 3D virtual environment. They are not allowed to communicate by talking or chatting, but only by interacting with shared virtual objects. We propose three solutions to enable one of the users to help the other one to navigate toward targets: displaying direction arrows, lighting up the path to one target, and remotely moving the second user.
\end{abstract}

Keywords: Collaborative 3D Interactions, Multi-Scale Shared Virtual Environments

Index Terms: H.5.3 [Information Interfaces and Presentation (e.g., HCI)]: Group and Organization Interfaces-Computersupported cooperative work (CSCW); I.3.6 [Computer Graphics]: Methodology and Techniques-Interaction techniques; I.3.7 [Computer Graphics]: 3-Dimensional Graphics and Realism-Virtual reality.

\section{INTRODUCTION}

In this study we propose a set of metaphors that enable several users to collaborate to achieve an exploration task in a 3D Virtual Environment (VE). This task consists in finding hidden objects in a multi-level building. We want both to minimize the time needed to achieve this quest by providing efficient collaboration metaphors, and to enable users to progressively discover the structure of the building. We respect the constraints imposed by the 3DUI 2012 contest: our users are not allowed to communicate together by talking or chatting, but only by sharing 3D virtual objects.

\section{The Scenario and the Users Roles}

We propose two asymmetric roles for our users: a main user, immersed in the virtual environment, and a helping user, in front of several 3D desktop views of the virtual environment (see figure 1). The scenario of the quest will be as follow: a target appears somewhere in the virtual building, the helping user must localize this target, and then must lead the main user to this target. Then a new

\footnotetext{
*e-mail:thi-thuong-huyen.nguyen@irisa.fr

†e-mail:cedric.fleury@irisa.fr

†e-mail:thierry.duval@irisa.fr
}

target will appear elsewhere only when the previous target will have been grabbed by the main user, and so on. The situations of these users can be compared to the mortal's view (for the main user) and the deity's miniaturized view (for the helping user) described in [5].

\subsection{The Main User}

$\mathrm{He}$ is in charge of grabbing the targets of the quest. He can navigate through the virtual environment but he has no map of it, and he does not know where the targets are hidden. So he needs help from other users to know in which direction he must search.

\subsection{The Helping User}

He can scan a 3D map of the virtual environment in order to find where the targets are hidden. He can not grab these targets by himself. So he needs to communicate with the first user to explain to him where the targets can be found.

\section{The Metaphors for 3D Collaboration}

\subsection{D Navigation}

We use a big CAVE-like system to fully immerse the main user in the 3D virtual environment: he uses a first person's point of view, and he can virtually navigate through the virtual environment with a walking metaphor using a joystick. As his head is tracked, he can also physically walk inside the cave to change his viewpoint. We use the IIVC metaphor [3] to make the difference between the virtual navigation (moving the physical stage of the user through the virtual environment with a virtual conveyor) and the physical navigation (physically moving the head of the user within his physical stage). We use collision detection to forbid the main user to navigate through the virtual objects of the virtual environment.

\subsection{Supervising the 3D Virtual World}

By increasing his scale, the helping user has a global view of the shared virtual environment that can be considered as a 3D map or as a World In Miniature (WIM) [6]. He can use a clipping plane to make a 3D scan of the VE to see where is the avatar of the main user and where is the target, in order to provide the main user with indications allowing him to find this target. This technique is similar to the clipping technique presented in [7].

This clipping plane is local to the process of the helping user (and so it is not shared with the main user), not to disturb the view of the main user during the $3 \mathrm{D}$ scan. 


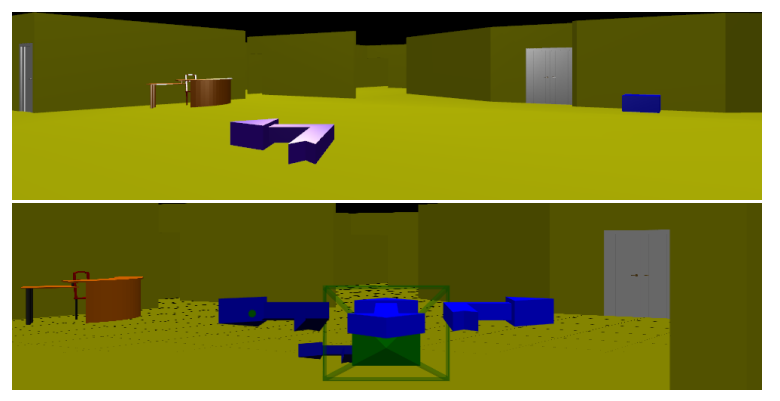

Figure 2: Direction arrows viewed from the main user view and from the helping user "over the shoulder" view

\subsection{Looking over the Shoulder of the Main User}

The helping user has a second view on the shared virtual environment, just behind the main user. The helping user will be able to give $3 \mathrm{D}$ indications to the main user through this second view.

\subsection{Leading the Main User to the Target}

\subsubsection{Providing 3D direction arrows}

Our first proposition is to provide to the helping user a 3D GUI made of direction arrows that he can select to make an ephemeral copy of one directional arrow appear just in front of the main user, to indicate in which direction the main user must go (see figure 2). This copy will be attached to the position of the main user but will keep its initial orientation to allow him to align precisely to this direction. As it is not always clear for the helping user that the main user understands his indications, the main user can acknowledge, through a $3 \mathrm{D}$ interaction (for example by selecting the ephemeral object), that he has understood the order.

\subsubsection{Lighting up the path}

Our second proposition is to allow the helping user to light up the path that leads to the target. It can be done through the WIM view of the helping user (see figure 3). In this case his "over the shoulder" view is used to verify that the main user perceives the light correctly.

\subsubsection{Remotely controlling the position of the main user}

Our third proposition is to allow the helping user to grab the conveyor of the main user to bring him near the next target. This technique could be interesting when the main user is slow or when he badly understands the indications given by the helping user.

\subsection{Acknowledging the finding of the target}

As it is not always clear for the helping user that the target has been grabbed, because his view can be sometimes occluded by the main user avatar or by virtual objects, the main user will acknowledge that he has grabbed the target: he will "glow". This can be done either automatically when he has grabbed the object, or through an explicit 3D interaction upon a 3D widget.

\section{Preliminary Evaluation and Experimental Setup}

To compare our three propositions about how to indicate to the main user the path toward the targets, several pairs of users will have to find 10 targets as quickly as possible with each technique, to determine which one is the most efficient. The main user is immersed within a big CAVE-like system, his head and his hands are tracked, he can interact thanks to a 3D cursor that he can trigger using a wiimote, and he can navigate using the joystick of the nunchunk associated to his wiimote. The helping user is located in another room, in front of two desktop screens: one for the global view and one for the view that follows the main user. He interacts with $3 \mathrm{D}$

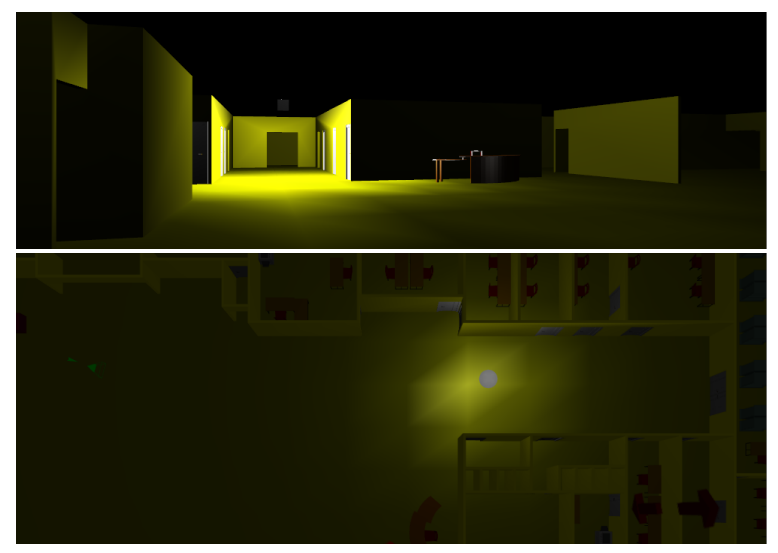

Figure 3: Lighted path viewed from the main user view and from the helping user WIM view

objects through 3D cursors or rays driven by a classical 2D mouse. We use the Collaviz framework to share the virtual environment between the two users: it is written in Java and uses Java3D [1] for the 3D desktop views and jReality [2] for the immersive view of the virtual environment. It manages several modes for distributing the virtual objects of the virtual environment over tcp or http [4].

\section{Perspectives}

These first results should show which method is the most efficient for leading a user in a multi-level building-like environment. We think that such a collaborative discovery should not only allow the main user to realize the finding task quickly, but should also make him able to travel by himself once this task has been completed several times. So next we plan to conduct complementary experiments in order to determine what are the clues for a good collaborative discovery of a virtual environment. To achieve this, we will propose other metaphors to help the user memorizing the structure of the virtual environment. For example he could put landmarks or other kinds of 3D annotations along his path while he travels across the virtual environment. These landmarks and $3 \mathrm{D}$ annotations could be displayed both in the main immersive view and in additional views such as a WIM view that could appear on the user's demand.

\section{ACKNOWLEDGEMENTS}

This work was partly funded by the French Research National Agency project named Collaviz (ANR-08-COSI-003-01).

\section{REFERENCES}

[1] The Java3D website. http://java3d.java.net/.

[2] The jReality website. http://www3.math.tu-berlin.de/jreality/.

[3] C. Fleury, A. Chauffaut, T. Duval, V. Gouranton, and B. Arnaldi. A Generic Model for Embedding Users' Physical Workspaces into MultiScale Collaborative Virtual Environments. In Proceedings of ICAT 2010, pages 1-8, 2010.

[4] C. Fleury, T. Duval, V. Gouranton, and B. Arnaldi. A New Adaptive Data Distribution Model for Consistency Maintenance in Collaborative Virtual Environments. In Proceedings of JVRC 2010, pages 29-36. Eurographics, 2010.

[5] J. Leigh, A. Johnson, C. Vasilakis, and T. DeFanti. Multi-perspective Collaborative Design in Persistent Networked Virtual Environments. In Proceedings of VRAIS'96, pages 253-260, 1996.

[6] R. Stoakley, M. J. Conway, and R. Pausch. Virtual Reality on a WIM: Interactive Worlds in Miniature. In Proceedings of CHI'95, pages 265272. ACM, 1995.

[7] R. Trueba, C. Andujar, and F. Argelaguet. Multi-scale Manipulation in Indoor Scenes with the World in Miniature Metaphor. In Proceedings of JVRC 2009, pages 93-100. Eurographics, 2009. 